\title{
FORMAÇÃO INICIAL EM NÍVEL SUPERIOR DOS CURSOS DE LICENCIATURA: EM PERSPECTIVA A GESTÃO EDUCACIONAL E ESCOLAR A PARTIR DA RESOLUÇÃO CNE/CP Nº 2/2015
}

\section{INITIAL FORMATION IN LICENTIATE DEGREE COURSE: IN PERSPECTIVE EDUCATIONAL AND SCHOOL MANAGEMENT FROM THE RESOLUTION CNE/CP N 2/2015}

Jeinni Kelly Pereira Puziol ${ }^{1}$

\section{RESUMO}

Este artigo discute possíveis impactos da Resolução CNE/CP n² de 01/07/2015 na formação inicial em nível superior dos cursos de licenciatura, de modo específico, problematiza a atuação e a participação dos profissionais do magistério na gestão e na organização das instituições de educação básica. O objetivo é destacar a dimensão da gestão educacional e escolar presente na referida resolução, de modo a refletir sobre a introdução desta especificidade formativa para todos os cursos de licenciatura, visto que na resolução anterior, CNE/CP nº1 de 18/02/2002, não era uma temática contemplada. Discute-se, assim, o Modelo de Gestão Autônoma da Escola, como fundamento do debate da política e da gestão educacional no Brasil, bem como possibilidades e dificuldades que as universidades poderão enfrentar, em específico, a Universidade Estadual de Maringá (UEM).

Palavras-chave: Política educacional. Gestão educacional. Gestão escolar.

\begin{abstract}
This article discusses the possible impacts of Resolution CNE/CP no. 2 of July 1 2015, on the initial formation licentiate degree course, in a specific way, problematizes the performance and participation of teachers in the management and organization of institutions. The objective is to highlight the dimension of the educational and school management present in this resolution, so as to reflect on the introduction of this formation specificity for all licentiate degree course, since in the previous resolution, $\mathrm{CNE} / \mathrm{CP} \mathrm{n}^{\circ} 1$ of 18 February 2002, was not a theme. It is briefly discussed the Model of Autonomous Management of School, as a basis for the debate on education policy and management in Brazil, as well as possibilities and difficulties that universities may face, specifically, the State University of Maringá (UEM).
\end{abstract}

Keywords: Educational politics. Educational management. School management.

\footnotetext{
${ }^{1}$ Professora adjunta do departamento de Teoria e Prática da Educação.
} 


\section{Reflexões Iniciais}

A formação de professores é assunto fundamental e constantemente debatido no cenário da educação brasileira, todavia, grande parte das discussões realizadas por educadores e educadoras, nos contextos da prática pedagógica e na pesquisa científica, não são incorporadas nas políticas públicas educacionais e assim, temos problemas que ao invés de temporários são permanentes. Nesse sentido, a Resolução $\mathrm{CNE} / \mathrm{CP}^{2} \mathrm{n}^{\mathrm{o}} 2$ de 01 de julho de 2015, que define as Diretrizes Curriculares Nacionais para a formação inicial em nível superior (cursos de licenciatura, cursos de formação pedagógica para graduados e cursos de segunda licenciatura) e para a formação continuada, traz um novo elemento para o debate sobre a formação de professores, que é incorporação de fundamentos e práticas da gestão educacional e escolar na formação do profissional do magistério.

Entende-se que uma formação que englobe fundamentos e práticas da gestão educacional e escolar é precípua na formação de profissionais do magistério de todas as licenciaturas, visto que tal prerrogativa, fica, sobretudo, sob a responsabilidade do curso de licenciatura em Pedagogia. Uma formação que envolva o aprendizado sobre a gestão e organização dos estabelecimentos escolares de modo mais aprofundado, pode propiciar que profissionais de outras licenciaturas atuem com maior qualidade e responsabilidade no estabelecimento escolar em sua totalidade e não somente em sala de aula, que já é grande comprometimento. Pode contribuir com a formação inicial do gestor, que deve ser acompanhada de problematizações sobre suas características no atual cenário político do país, para que a gestão democrática incorporada à Constituição Federal de 1988 e à Lei de Diretrizes e Bases da Educação Nacional 9394/96 não seja apenas uma retórica.

Assim, este artigo discute os possíveis impactos da Resolução CNE/CP no 2 de 01 de julho de 2015 na formação inicial dos cursos de nível superior, na modalidade licenciatura, no que concerne a atuação e a participação dos profissionais do magistério na gestão e na organização das instituições de educação básica. O objetivo é destacar a dimensão da gestão educacional e escolar presente na referida resolução, de modo a problematizar sobre a introdução desta especificidade formativa para todos os cursos de licenciatura, visto que na resolução anterior, $\mathrm{CNE} / \mathrm{CP} \mathrm{n}^{\circ} 1$ de 18 de fevereiro de 2002, não era uma temática contemplada de modo explícito e delimitado como agora.

\footnotetext{
${ }^{2}$ CNE: Conselho Nacional de Educação; CP: Conselho Pleno.
} 
O texto está divido em três partes: a primeira teoriza sobre o Modelo de Gestão Autônoma da Escola (GAE), de modo a compreender este terreno de debate e atuação tão fundamental na formação de professores; a segunda parte apresenta os elementos da Resolução CNE/CP n 2 (BRASIL, 2015) no que diz respeito a gestão educacional e escolar; e por fim problematiza-se sobre os impactos da inserção da gestão como prerrogativa de formação inicial nos cursos de licenciatura, destacando a importância da área de gestão educacional e escolar nas Instituições de Educação Superior (IES), bem como as dificuldades que poderão enfrentar para suprir possíveis demandas dos cursos de licenciatura no futuro próximo. Nesta última parte destaca-se o cenário da Universidade Estadual de Maringá (UEM).

\section{Cenário de governança multiescalar: Modelo de Gestão Autônoma da Escola}

A reforma do aparelho do Estado brasileiro, realizada em meados da década de 1990, sob os ajustes estruturais do neoliberalismo, da financeirização e da reestruturação produtiva, possibilitou a incorporação cada vez mais comum de políticas educacionais elaboradas por organizações supranacionais. Este mecanismo é característico do cenário de governança multiescalar, cenário em que o Estado, cada vez mais heterogêneo, “[...] é associado com elementos transnacionais, assim como nacionais e subnacionais" (DALE, 2014, p. 7). A governança, exercida em diferentes escalas, - global, nacional, regional e local - é marcada pelo deslocamento das instâncias de poder, em que são desterritorializadas e reterritorializadas políticas educacionais, que ora exercem influência sob políticas nacionais, ora são incorporadas ao contexto da prática ou mesmo rechaçadas por atores de cenários nacionais ou locais.

Neste contexto, de influência de muitas escalas de poder na elaboração de políticas educacionais, em que organizações como UNESCO, UNICEF, Banco Mundial e Fundo Monetário Internacional, ou blocos regionais como a União Europeia, exercem ascendência sobre governos, a gestão educacional é também alvo de teorizações e realizações práticas. Assim, atualmente, no âmbito da gestão educacional e escolar, tem-se, uma tendência em escala global, disseminada por estudo patrocinado pela Organização das Nações Unidas para a Educação, a Ciência e a Cultura (UNESCO), o Modelo de Gestão Autônoma (GAE) (ADUDUHOU, 2002).

O Modelo de Gestão Autônoma da Escola é baseado nos princípios de eficiência, eficácia, centralidade, auto-gestão e avaliação contínua do desempenho. Também pode-se acrescentar, que este modelo se apresenta como algo desvinculado da política, buscando a 
formação da figura do gestor descolada da atuação política fundamentalmente necessária. Entende-se que é impossível desvincular a gestão da política educacional, de modo que tal desvinculação só favorece os discursos que visam transformar a escola em um mercado. A exemplo da política nacional brasileira, vê-se que um dos candidatos que mais vendeu a figura de gestor desvinculado de política, João Dória Júnior, foi um dos sujeitos que mais realizam política excludente nos últimos anos.

De acordo com Fonseca, Oliveira e Toschi (2004), os preceitos do GAE tem aproximado cada vez mais a escola pública de fundamentos das organizações privadas. Para os referidos autores, no Modelo de Gestão Autônoma a Escola,

[...] as instituições públicas são exortadas a trilhar novos caminhos organizacionais, na linha da 'auto-gestão' e que as aproximem das suas congêneres do setor privado; multiplicam-se as propostas de avaliação do desempenho escolar, medido pelo rendimento dos alunos em testes padronizados; professores são estimulados a participar de atividades que não se limitem à sala de aula, mas que se destinem à própria organização da escola como um todo (FONSECA, OLIVEIRA e TOSCHI, 2004, p. 53).

Considerando a gestão como um "[...] conjunto de intervenções, decisões e processos com certo grau de intencionalidade e sistematização, tentando modificar atitudes, ideias, culturas, conteúdos, modelos organizacionais e práticas pedagógicas" (FONSECA, OLIVEIRA E TOSCHI, 2004), a adoção do modelo GAE leva para as escolas os princípios organizacionais do mercado, das empresas. Essa tendência da gestão educacional ganhou espaço na política brasileira, que mesmo sob o signo da gestão democrática, presentes na Constituição Federal de 1988 e na Lei de Diretrizes e Bases da Educação Nacional 9394/96, tem expressado no contexto da prática uma centralização das decisões na figura do diretor/gestor e uma busca incessante pela contabilização do desempenho de alunos e professores a partir de avaliações e ranqueamentos nacionais.

Para Ball (2012), o atual cenário educacional global é marcado por uma incitação a performatividade, um mecanismo chave da gestão neoliberal, e, por conseguinte do GAE, baseado em comparações e julgamentos. Mesmo sob o discurso da gestão democrática os indivíduos são instados a competir, de modo que a ideia de performatividade "[...] abrange a subjetividade, as práticas institucionais, a economia e o governo. É tanto individualizante quanto totalizante. Ela produz docilidade ativa e produtividade sem profundidade”. De acordo com Ball (2012, p. 67), a performatividade, 
[...] trata-se de transformar o indivíduo em uma empresa, como sugerido anteriormente, em uma unidade produtiva de automaximização que opera em um mercado de desempenhos - comprometido, mais flexível do que preso a princípios - essencialmente sem profundidade. A consequência de estímulo e de cálculo contínuos é, para muitos, uma crescente sensação de insegurança ontológica; tanto a perda do sentido do significado do que fazemos quando a importância do que fazemos. Dentro de tudo isso, a organização, escola, faculdade, universidade, agência - e o indivíduo são tratados exatamente da mesma maneira.

Diante do cenário de hibridismo político, em que decisões são elaboradas em diversas escalas de poder, em que a gestão é vista como uma ferramenta técnica desvinculada da política e voltada a transformação da escola em uma empresa, pautada em eficiência, eficácia e avaliação de desempenho, é possível dimensionar a importância da formação inicial dos cursos de licenciatura para atuação e participação dos processos de gestão educacional e escolar. A realização da gestão democrática, pautada em princípios de igualdade, divisão de responsabilidade e participação efetiva da comunidade escolar, se efetiva na realidade concreta e não apenas na formalidade legislativa (PARO, 2007; 2016).

Em síntese, no cenário da governança multiescalar, exercida em redes, "a política educacional está sendo 'feita' em novas localidades, em diferentes parâmetros, por novos atores e organizações" (BALL, 2012, p. 27). E a gestão educacional e escolar, respectivamente relacionadas a escala macro e micro, intrinsecamente ligadas a política educacional, encontrase hegemonicamente vinculada a ideias empresariais, demandando das escolas eficiência e eficácia pautada nos princípios da performatividade.

O questionamento que se faz, é como as disciplinas de gestão educacional podem aproveitar a prerrogativa da formação para atuação e participação na gestão das instituições de educação básica por todas as licenciaturas, para encaminhar este debate e propor processos de gestão contra-hegemônicos, em que a gestão sob princípios democráticos não seja apenas uma retórica. Como a área de gestão educacional e escolar presentes nas IES, podem aproveitar o conteúdo da resolução $\mathrm{CNE} / \mathrm{CP}$ n² de 2015 para além da concepção hegemônica de gestão e propor uma formação ainda mais complexa ao futuro educador?

\section{Atuação e participação na gestão das instituições de educação básica: a Resolução $\mathrm{CNE} / \mathrm{CP} \mathrm{n}^{\circ} 2$ de 2015}

A Resolução CNE/CP no 2 de 2015, em substituição da Resolução CNE/CP nº 1 de 2002, define as Diretrizes Curriculares Nacionais para a formação inicial em nível superior (cursos de licenciatura, cursos de formação pedagógica para graduados e cursos de segunda 
licenciatura) e para a formação continuada. A Resolução CNE/CP n 2 de 2015, em vigência, possui 25 artigos divididos em oito capítulos, a saber: Das Disposições Gerais; Formação dos Profissionais do Magistério para Educação Básica: Base Comum Nacional; Do(a) Egresso(a) da Formação Inicial e Continuada; Da Formação Inicial do Magistério da Educação Básica em Nível Superior; Da Formação Inicial do Magistério da Educação Básica em Nível Superior: Estrutura e Currículo; Da Formação Continuada dos Profissionais do Magistério; Dos Profissionais do Magistério e sua Valorização; e Das Disposições Transitórias.

A dimensão destacada da Resolução CNE/CP n 2 de 2015, que não era contemplada na resolução anterior, é a definição da gestão educacional dos sistemas de ensino e das unidades escolares de educação básica, nas diversas etapas e modalidades de educação, como atividade pedagógica dos profissionais do magistério da educação básica. Até a publicação da referida resolução, a formação inicial para a participação na organização e gestão de sistemas e instituições de ensino era característica dos cursos de licenciatura em Pedagogia, estabelecido pela Resolução CNE/CP n ${ }^{\circ}$, de 15 de maio de 2006, que institui as Diretrizes Curriculares Nacionais para o Curso de Graduação em Pedagogia, licenciatura.

Assim, a partir de 2015, todos os cursos de licenciatura, formação inicial e continuada, deve possibilitar formação na área de gestão de processos educativos e organização e gestão de instituições de educação básica. No capítulo que trata das Disposições Gerais, de acordo com Art. $3^{\circ}$, "A formação inicial e a formação continuada deverão possibilitar, entre outros elementos, a realização da gestão democrática” (BRASIL, 2015, p. 3). Neste mesmo artigo, § $4^{\circ}$, é estabelecido que

Os profissionais do magistério da educação básica compreendem aqueles que exercem atividades de docência e demais atividades pedagógicas, incluindo a gestão educacional dos sistemas de ensino e das unidades escolares de educação básica (educação infantil, ensino fundamental, ensino médio, educação de jovens e adultos, educação especial, educação profissional e técnica de nível médio, educação escolar indígena, educação do campo, educação escolar quilombola e educação a distância) [...] (BRASIL, 2015, p. 4).

No capítulo III, que trata do egresso da formação inicial e continuada, faz parte das diretrizes expressas pela Resolução, em seu art. $8^{\circ}$, inciso IX, que os egressos provenientes dos cursos de formação inicial em nível superior deverão estar aptos a "atuar na gestão e organização das instituições de educação básica, planejando, executando, acompanhando e avaliando políticas, projetos e programas educacionais" (BRASIL, 2015, p. 8). Também, de 
acordo com inciso X, art. $8^{\circ}$, deve estar qualificado para "participar da gestão das instituições de educação básica, contribuindo para a elaboração, implementação, coordenação, acompanhamento e avaliação do projeto pedagógico" (BRASIL, 2015, p. 8).

Sobre a formação inicial do magistério da educação básica em nível superior, correspondente ao capítulo IV, de acordo com o art. 10, parágrafo único, "As atividades do magistério também compreendem a atuação e participação na organização e gestão de sistemas de educação básica e suas instituições de ensino [...]" (BRASIL, 2015, p. 9). Tais atividades do magistério, englobam, de acordo com os incisos I e II do art. 10, "planejamento, desenvolvimento, coordenação, acompanhamento e avaliação de projetos, do ensino, das dinâmicas pedagógicas e experiências educativas; produção e difusão do conhecimento científico-tecnológico das áreas específicas e do campo educacional” (BRASIL, 2015, p. 9).

Outro elemento definido pela Resolução $\mathrm{CNE} / \mathrm{CP} \mathrm{n}^{\circ} 2$ de 2015, é o estabelecimento de núcleos para a formação inicial em nível superior. Destaca-se atividades no âmbito da gestão educacional presentes em tais núcleos definidos no art. 12, incisos I e II. No primeiro núcleo, "[...] de estudos de formação geral, das áreas específicas e interdisciplinares, e do campo educacional, seus fundamentos e metodologias, e das diversas realidades educacionais [...]", fica estabelecida a pesquisa e o estudo da legislação educacional e de processos de organização e gestão, bem como a aplicação a avaliação da legislação e produção específica sobre organização e gestão da educação nacional.

No segundo núcleo, "de aprofundamento e diversificação de estudos das áreas de atuação profissional, incluindo os conteúdos específicos e pedagógicos, priorizadas pelo projeto pedagógico das instituições [...]”, oportunizará a investigações sobre processos educativos, organizacionais e de gestão na área educacional (BRASIL, 2015, p. 10).

Percebe-se, a partir do conteúdo da resolução CNE/CP nº 2 de 2015, que a temática da gestão educacional e escolar, até então prerrogativa da formação do pedagogo, está presente também na formação inicial de todos os cursos de licenciatura. Destaca-se que na licenciatura em Pedagogia, a área de gestão educacional e escolar, é contemplada de modo mais aprofundado, contando inclusive com o estágio curricular supervisionado. No âmbito das licenciaturas em geral, os cursos poderão solicitar a formação específica na área de gestão para os departamentos/faculdades de educação de suas universidades. Com esta resolução abre-se novas possibilidades formativas para os cursos de licenciatura. 


\section{Gestão educacional e escolar na formação dos profissionais do magistério: elementos para o debate}

Diante deste contexto, abre-se um novo campo de atuação da área da educação nos cursos de licenciatura, espaço que já existe para a área de política educacional, em que é trabalhada a estrutura, o funcionamento e a organização da educação brasileira. A área de gestão educacional e escolar poderá propor aos cursos uma disciplina que contemple a formação em gestão presente na resolução, o que poderá, a longo prazo, auxiliar na formação de gestores/diretores escolares e professores que compreendam a escola em sua totalidade.

A área de gestão, trabalhando sob uma perspectiva crítica, poderá constituir um espaço formativo nas licenciaturas de questionamento do Modelo de Gestão Autônomo da Escola apontado suas contradições e outros caminhos, dialogando com as políticas educacionais e sua complexidade multiescalar.

No caso da Universidade Estadual de Maringá ${ }^{3}$ (UEM), as mudanças propostas pela resolução CNE/CP no 2 de 2015, rebaterá na área de Gestão Educacional do Departamento de Fundamentos da Educação (DFE). Na UEM, além da licenciatura em Pedagogia, atendida pela área de Gestão Educacional, há outras 14 licenciaturas dentre seus 75 cursos de graduação nas modalidades presencial, a distância e PARFOR ${ }^{4}$.

Nos quadro a seguir é possível visualizar os cursos de graduação na modalidade licenciatura que são ofertados pela UEM no campus sede.

\begin{tabular}{|c|c|c|c|}
\hline Cursos & Disciplina & Ano & $\begin{array}{l}\text { Carga- } \\
\text { horária }\end{array}$ \\
\hline Artes Cênicas (vespertino) & $\begin{array}{l}\text { Políticas Públicas e Educação } \\
\text { Brasileira }\end{array}$ & $2^{\circ}$ & $68 \mathrm{~h}$ \\
\hline Artes Visuais (vespertino) & $\begin{array}{l}\text { Políticas Públicas no Ensino } \\
\text { da Arte }\end{array}$ & $3^{\circ}$ & $68 \mathrm{~h}$ \\
\hline $\begin{array}{l}\text { Ciências Biológicas } \\
\text { (integral/noturno) }\end{array}$ & $\begin{array}{l}\text { Políticas Públicas e Gestão } \\
\text { Educacional }\end{array}$ & $1^{\mathrm{o}}$ & $68 \mathrm{~h}$ \\
\hline Ciências Sociais (noturno) & $\begin{array}{l}\text { Políticas Públicas e Gestão } \\
\text { Educacional }\end{array}$ & $4^{\circ}$ & $68 \mathrm{~h}$ \\
\hline $\begin{array}{l}\text { Educação Física } \\
\text { (integral/noturno) }\end{array}$ & $\begin{array}{l}\text { Políticas Públicas e Gestão } \\
\text { Educacional para Docência em } \\
\text { Educação Física }\end{array}$ & $4^{\circ}$ & $68 \mathrm{~h}$ \\
\hline
\end{tabular}

\footnotetext{
${ }^{3}$ A Universidade Estadual de Maringá - UEM, é uma universidade pública fundada em 1969 e mantida pelo Estado do Paraná.

${ }^{4}$ Por ausência de informações não foram utilizados os dados desta modalidade.
} 


\begin{tabular}{|c|c|c|c|}
\hline Filosofia (vespertino) & $\begin{array}{l}\text { Políticas Públicas e Gestão } \\
\text { Educacional }\end{array}$ & $1^{\mathrm{o}}$ & $68 \mathrm{~h}$ \\
\hline Física (noturno) & $\begin{array}{l}\text { Políticas Públicas e Gestão } \\
\text { Educacional }\end{array}$ & $3^{\circ}$ & $85 \mathrm{~h}$ \\
\hline Geografia (matutino/noturno) & $\begin{array}{l}\text { Políticas Públicas e Gestão } \\
\text { Educacional }\end{array}$ & $3^{\circ}$ & $68 \mathrm{~h}$ \\
\hline História (matutino/noturno) & Nenhuma & - & - \\
\hline Letras (matutino/noturno) & $\begin{array}{l}\text { Políticas Públicas e Gestão } \\
\text { Educacional }\end{array}$ & $\begin{array}{l}1^{\circ} \text { ou } 2^{\circ} \text { ano } \\
\text { (depende } \\
\text { da } \\
\text { habilitação) }\end{array}$ & $68 \mathrm{~h}$ \\
\hline Matemática (integral/noturno) & $\begin{array}{l}\text { Políticas Públicas e Gestão } \\
\text { Educacional }\end{array}$ & $3^{\circ}$ & $68 \mathrm{~h}$ \\
\hline Música (integral) & $\begin{array}{l}\text { Políticas Públicas e Gestão } \\
\text { Educacional }\end{array}$ & $2^{o}$ & $68 \mathrm{~h}$ \\
\hline \multirow{11}{*}{ Pedagogia (matutino/noturno) } & $\begin{array}{l}\text { Políticas Públicas e Gestão } \\
\text { Educacional: Identidade do } \\
\text { Pedagogo nos Processos } \\
\text { Escolares e Não Escolares }\end{array}$ & $1^{\mathrm{o}}$ & $68 \mathrm{~h}$ \\
\hline & $\begin{array}{l}\text { Planejamento, Gestão } \\
\text { Educacional e Atuação do } \\
\text { Pedagogo como Gestor na } \\
\text { Educação Básica }\end{array}$ & \multirow{4}{*}{$2^{\circ}$} & $68 \mathrm{~h}$ \\
\hline & $\begin{array}{l}\text { Políticas, Gestão e } \\
\text { Diversidade }\end{array}$ & & $34 \mathrm{~h}$ \\
\hline & $\begin{array}{l}\text { Práticas de Gestão: } \\
\text { Organização dos Trabalhos } \\
\text { Pedagógicos }\end{array}$ & & $34 \mathrm{~h}$ \\
\hline & $\begin{array}{l}\text { Estágio Curricular } \\
\text { Supervisionado de Gestão I }\end{array}$ & & $34 \mathrm{~h}$ \\
\hline & $\begin{array}{l}\text { Organização da Gestão } \\
\text { Escolar }\end{array}$ & \multirow{2}{*}{$3^{\circ}$} & $34 \mathrm{~h}$ \\
\hline & $\begin{array}{l}\text { Políticas Públicas e Gestão da } \\
\text { Educação Brasileira }\end{array}$ & & $34 \mathrm{~h}$ \\
\hline & $\begin{array}{l}\text { Políticas Públicas e Gestão } \\
\text { Educacional: Docência e } \\
\text { Diversidade Cultural }\end{array}$ & \multirow{3}{*}{$4^{\circ}$} & $68 \mathrm{~h}$ \\
\hline & $\begin{array}{l}\text { Práticas de Gestão: } \\
\text { Planejamento e Avaliação } \\
\text { Escolar }\end{array}$ & & $34 \mathrm{~h}$ \\
\hline & $\begin{array}{l}\text { Estágio Curricular } \\
\text { Supervisionado de Gestão II }\end{array}$ & & $68 \mathrm{~h}$ \\
\hline & \multicolumn{3}{|c|}{ Total: $408 \mathrm{~h}$} \\
\hline Química (noturno) & $\begin{array}{l}\text { Políticas Públicas e Gestão } \\
\text { Educacional }\end{array}$ & $1^{\mathrm{o}}$ & $34 \mathrm{~h}$ \\
\hline
\end{tabular}

Além dos cursos de licenciatura do campus sede, também são apresentados os cursos ofertados no Campus Regional de Cianorte, localizado a 86km do município de Maringá.

Quadro 2 - Cursos de Licenciatura do Campus Regional de Cianorte - PR 


\begin{tabular}{|c|c|c|c|}
\hline Cursos & Disciplina & Ano & $\begin{array}{l}\text { Carga- } \\
\text { horária }\end{array}$ \\
\hline \multirow{10}{*}{ Pedagogia (noturno) } & $\begin{array}{l}\text { Políticas Públicas e Gestão } \\
\text { Educacional: Identidade do } \\
\text { Pedagogo nos Processos } \\
\text { Escolares e Não Escolares }\end{array}$ & $1^{\mathrm{o}}$ & $68 \mathrm{~h}$ \\
\hline & $\begin{array}{l}\text { Planejamento, Gestão } \\
\text { Educacional e Atuação do } \\
\text { Pedagogo como Gestor na } \\
\text { Educacão Básica }\end{array}$ & \multirow{4}{*}{$2^{\circ}$} & $68 \mathrm{~h}$ \\
\hline & $\begin{array}{l}\text { Políticas, Gestão e } \\
\text { Diversidade }\end{array}$ & & $34 \mathrm{~h}$ \\
\hline & $\begin{array}{l}\text { Práticas de Gestão: } \\
\text { Organização dos Trabalhos } \\
\text { Pedagógicos }\end{array}$ & & $34 \mathrm{~h}$ \\
\hline & $\begin{array}{l}\text { Estágio Curricular } \\
\text { Supervisionado de Gestão I }\end{array}$ & & $34 \mathrm{~h}$ \\
\hline & $\begin{array}{l}\text { Organização da Gestão } \\
\text { Escolar }\end{array}$ & \multirow{2}{*}{$3^{\circ}$} & $34 \mathrm{~h}$ \\
\hline & $\begin{array}{l}\text { Políticas Públicas e Gestão da } \\
\text { Educação Brasileira }\end{array}$ & & $34 \mathrm{~h}$ \\
\hline & $\begin{array}{l}\text { Políticas Públicas e Gestão } \\
\text { Educacional: Docência e } \\
\text { Diversidade Cultural }\end{array}$ & \multirow{3}{*}{$4^{\circ}$} & $68 \mathrm{~h}$ \\
\hline & $\begin{array}{l}\text { Práticas de Gestão: } \\
\text { Planejamento e Avaliação } \\
\text { Escolar }\end{array}$ & & $34 \mathrm{~h}$ \\
\hline & $\begin{array}{l}\text { Estágio Curricular } \\
\text { Supervisionado de Gestão II }\end{array}$ & & $68 \mathrm{~h}$ \\
\hline
\end{tabular}

O Campus Regional de Goioerê possui duas licenciaturas e está a 176km do município de Maringá.

Quadro 3 - Cursos de Licenciatura dos Campus Regional de Goioerê - PR

\begin{tabular}{|l|l|l|l|}
\hline Cursos & Disciplina & Ano & $\begin{array}{l}\text { Carga- } \\
\text { horária }\end{array}$ \\
\hline Física (noturno) & $\begin{array}{l}\text { Políticas Públicas e Gestão } \\
\text { Educacional }\end{array}$ & $4^{\circ}$ & $68 \mathrm{~h}$ \\
\hline Licenciatura Plena em Ciências & $\begin{array}{l}\text { Políticas Públicas e Gestão } \\
\text { Educacional }\end{array}$ & $3^{\circ}$ & $68 \mathrm{~h}$ \\
\hline
\end{tabular}

Quadro 4 - Cursos de Licenciatura dos Campus Regional do Vale do Ivaí - PR

\begin{tabular}{|l|l|l|l|}
\hline Cursos & Disciplina & Ano & $\begin{array}{l}\text { Carga- } \\
\text { horária }\end{array}$ \\
\hline Educação Física (integral) & $\begin{array}{l}\text { Políticas Públicas e Gestão } \\
\text { Educacional para Docência em } \\
\text { Educação Física }\end{array}$ & $4^{\circ}$ & $68 \mathrm{~h}$ \\
\hline História (noturno) & - & - & - \\
\hline
\end{tabular}


Além dos cursos presenciais há também as licenciaturas na modalidade a distância, ofertadas em 30 municípios diferentes - Polos de Apoio Presencial - UAB.

Quadro 5 - Cursos de Licenciatura na Modalidade a Distância

\begin{tabular}{|l|l|l|l|}
\hline Cursos & Disciplina & Ano & $\begin{array}{l}\text { Carga- } \\
\text { horária }\end{array}$ \\
\hline Ciências Biológicas & $\begin{array}{l}\text { Políticas Públicas e Gestão } \\
\text { Educacional }\end{array}$ & $3^{\circ}$ & $68 \mathrm{~h}$ \\
\hline Física & $\begin{array}{l}\text { Políticas Públicas e Gestão } \\
\text { Educacional }\end{array}$ & $3^{\circ}$ & $68 \mathrm{~h}$ \\
\hline História & - & - & - \\
\hline Letras & $\begin{array}{l}\text { Políticas Públicas e Gestão } \\
\text { Educacional }\end{array}$ & $3^{\circ}$ & $68 \mathrm{~h}$ \\
\hline \multirow{3}{*}{ Pedagogia } & Gestão Educacional & $2^{\circ}$ & $102 \mathrm{~h}$ \\
\cline { 2 - 4 } & \begin{tabular}{l} 
Política Educacional Brasileira \\
\cline { 2 - 3 }
\end{tabular} & $\begin{array}{l}\text { Gestão do Trabalho } \\
\text { Pedagógico }\end{array}$ & $68 \mathrm{~h}$ \\
\cline { 2 - 4 } & $\begin{array}{l}\text { Estágio Supervisionado VI }- \\
\text { Gestão }\end{array}$ & $102 \mathrm{~h}$ \\
\cline { 2 - 4 } & & $68 \mathrm{~h}$ \\
\hline
\end{tabular}

Verifica-se que o curso de Pedagogia, como já mencionado anteriormente, possui uma carga-horária maior para tratar da especificidade da política e gestão educacional, pois de acordo com as diretrizes curriculares específicas do curso é central em sua formação "[...] a participação na gestão de processos educativos e na organização e funcionamento de sistemas e instituições de ensino" (BRASIL, 2006, p. 1).

Exceto o curso de História, todos os outros possuem em seu currículo a disciplina de Políticas Públicas e Gestão Educacional (com alguma variação de nomenclatura devido as necessidades de determinados cursos) que é ofertada pelo Departamento de Teoria e Prática da Educação (DTP). Na maioria dos cursos a disciplina é de 68h, exceto os cursos de Química (34h) e Física (85h).

O conteúdo desta disciplina, constitui-se, predominantemente em: Constituições Federais do Brasil, Leis e Diretrizes da Educação Nacional, Estatuto da Criança e do Adolescente, Diretrizes Curriculares para Formação de Professores nas Licenciaturas (variando de acordo com cada curso), Organização Administrativa e Acadêmica, Gestão Escolar, Projeto Pedagógico, Formação profissional e mercado de trabalho. Trata-se de uma disciplina que objetiva subsidiar a formação para a docência com conhecimentos teórico-práticos referentes às políticas públicas educacionais e sua relação com o contexto sócio-político e econômico no âmbito estrutural e conjuntural. 
Desse modo, a especificidade da área de gestão educacional e escolar, como propõe a resolução CNE/CP nº 2 de 2015, não é contemplada pela disciplina de Políticas Públicas e Gestão Educacional, visto que não há carga-horária suficiente para a expansão da ementa. Temáticas fundamentais na formação do licenciado como, fundamentos e processos do planejamento educacional, as teorias da administração escolar e gestão educacional, as distinções entre gestão educacional, gestão escolar e gestão democrática, a figura do pedagogo gestor na Educação Básica e as instâncias colegiadas na escola, poderão ser trabalhadas de acordo com as demandas da nova resolução.

Assim, concordamos com Dourado (2015, p. 316) ao apontar que há avanços na comparação da Resolução no 1 de 2002 com a atual (Resolução no 2 de 2015), de modo que as atuais diretrizes,

[...] enfatizam a necessária articulação entre educação básica e superior, bem como, a institucionalização de projeto próprio de formação inicial e continuada dos profissionais do magistério da educação básica, por parte das instituições formadoras, tendo por eixo concepção formativa e indutora de desenvolvimento institucional que redimensiona a formação desses profissionais a partir de concepção de docência que inclui o exercício articulado nos processos ensino e aprendizagem e na organização e gestão da educação básica.

Todavia, é necessário questionar, de que forma as IES, de modo geral, vão suprir mais uma dimensão da formação docente, neste caso a gestão educacional e escolar, diante de um cenário de precarização das universidades e faculdades estaduais e federais? Como as áreas de gestão e política educacional vão suprir possíveis aumentos de carga-horária sem expansão docente? No cenário de escassez de concursos públicos, professores aprovados em concursos antigos e não nomeados, professores temporários com carga-horária excessiva impossibilitando a pesquisa (e mesmo as aulas diante do trabalho com ementas e programas distintos de sua área de pesquisa), como pensar uma formação inicial de professores mais complexificada diante dos cortes de investimentos nas IES públicas?

\section{Reflexões finais}

Em síntese, diante do conteúdo da resolução CNE/CP no 2 de 2015, percebe-se um avanço com relação as diretrizes para a formação inicial de professores, aprofundando um aspecto da formação docente tão essencial ao cenário da educação básica: a dimensão da gestão educacional e escolar. A possibilidade de abordar, de modo mais específico, a gestão educacional e escolar em todos os cursos de licenciatura, pode se configurar numa importante 
ação docente formativa que favoreça o entendimento da realização das políticas educacionais no contexto da prática, dando maior materialidade à legislação educacional.

O debate que as áreas de política e gestão educacional e escolar podem aprofundar no âmbito das licenciaturas, pode auxiliar na formação de professores que acreditem na política e na gestão como a arte do diálogo, não como temáticas salvacionistas, mas como a realização do possível no necessário horizonte da utopia. No caso da UEM, colocada como exemplo, a área de gestão educacional pode aprofundar o seu debate em 14 cursos de licenciatura, de modo a contribuir com uma formação docente mais complexificada, levando para além da Pedagogia, a preocupação com a organização da escola em sua totalidade.

Entretanto, é necessário refletir sobre o cenário de governança multiescalar que constitui as políticas educacionais, e, por conseguinte, a gestão educacional, marcado por uma tendência empresarial que leva o setor educacional público a reproduzir práticas características do mercado. A visão de gestão educacional e escolar predominante em orientações supranacionais, como o já mencionado Modelo de Gestão Autonôma da Escola, não é aquela deve orientar a formação de professores, mas sim aquela que deve ser questionada, a fim de constituir uma prática de gestão que seja de fato democrática e constitua uma escola que avalia aquilo que ensina e não ensine apenas aquilo que avalia.

Também é basilar considerar as dificuldades enfrentadas pelas IES no atual cenário político e econômico do Brasil, de modo a ponderar que as áreas de gestão educacional e escolar podem enfrentar dificuldades quanto a expansão de carga-horária. Para que a formação de professores seja realizada de forma responsável é necessário que os investimentos nas IES sejam ampliados e não reduzidos, como tem acontecido no cenário de austeridade e precariedade da UEM e da maioria das universidades e faculdades públicas do Brasil. Faz-se necessário reescalar a luta pela universidade pública de qualidade que incide diretamente sobre a formação de professores, de modo que as próximas décadas sejam também propositivas e não apenas lamentações. 


\section{REFERÊNCIAS}

ABU-DUHOU, Ibtsan. Uma gestão mais autônoma das escolas. Brasília: UNESCO/IIEP, 2002.

BALL, Stephen. Educação global S.A.: novas redes políticas e o imaginário neoliberal. Ponta Grossa: Editora UEPG, 2012.

BARROSO, João. Exposição no II Congresso de Política e Administração da Educação. Universidade do Minho, Braga. Jan. 2001.

BRASIL. Constituição da República Federativa do Brasil. São Paulo: Rideel, 2016.

BRASIL. Conselho Nacional de Educação. Define as Diretrizes Curriculares Nacionais para a formação inicial em nível superior (cursos de licenciatura, cursos de formação pedagógica para graduados e cursos de segunda licenciatura) e para a formação continuada. Resolução

CNE/CP n. 01, de 18 de fevereiro de 2002. Brasília, Diário Oficial [da] República Federativa do Brasil, 18 de fevereiro de 2002. Disponível em:

<http://portal.mec.gov.br/seesp/arquivos/pdf/res1_2.pdf>.

BRASIL. Conselho Nacional de Educação. Institui Diretrizes Curriculares Nacionais para o Curso de Graduação em Pedagogia, licenciatura. Resolução CNE/CP n ${ }^{\mathbf{0}}$ 1, de 15 de maio de 2006. Brasília, Diário Oficial [da] República Federativa do Brasil, seção 1, n. 92, p. 11, 16 de Maio de 2006. Disponível em: <http://portal.mec.gov.br/cne/arquivos/pdf/rcp01_06.pdf>.

BRASIL. Conselho Nacional de Educação. Define as Diretrizes Curriculares Nacionais para a formação inicial em nível superior (cursos de licenciatura, cursos de formação pedagógica para graduados e cursos de segunda licenciatura) e para a formação continuada. Resolução CNE/CP n. 02/2015, de $1^{\circ}$ de julho de 2015. Brasília, Diário Oficial [da] República Federativa do Brasil, seção 1, n. 124, p. 8-12, 02 de julho de 2015. Disponível em: $<$ http://pesquisa.in.gov.br/imprensa/jsp/visualiza/index.jsp?data=02/07/2015\&jornal=1\& pagina $=8 \&$ totalArquivos $=72>$.

BRASIL. Lei de Diretrizes e Bases da Educação Nacional. Lei n. 9394, 20 de dezembro de 1996.

DALE, Roger. Globalização e educação: demonstrando a existência de uma "cultura educacional mundial comum" ou localizando uma "agenda globalmente estruturada para a educação”? Educ. Soc., Campinas, vol. 25, n. 87, p. 423-460, maio/ago. 2004. 
DOURADO, Luis Fernandes. Diretrizes curriculares nacionais para a formação inicial e continuada dos profissionais do magistério da educação básica: concepções e desafios. Educ. Soc., Campinas, v. 36, nº 131, p. 299-324, abr.-jun., 2015.

FONSECA, Marília; OLIVEIRA, João Ferreira; TOSCHI, Mirza Seabra. As tendências da gestão na atual política educacional brasileira: autonomia e controle? In: OLIVEIRA, João Ferreira de; BITTAR, Mariluce. Gestão e Políticas da Educação. Rio de Janeiro: DP\&A, 2004.

PARO, Vitor Henrique. Administração escolar: uma introdução crítica. São Paulo: Cortez, 2007.

PARO, Vitor Henrique. Gestão Democrática da Escola Pública. São Paulo: Cortez, 2016. 